\title{
Understanding Implementation of Complex Interventions in Primary Care Teams
}

\author{
Thea Luig, PhD, Jodie Asselin, PhD, Arya M. Sharma, MD, PhD, and \\ Denise L. Campbell-Scherer, $M D, P b D$
}

Background: The implementation of interventions to support practice change in primary care settings is complex. Pragmatic strategies, grounded in empiric data, are needed to navigate real-world challenges and unanticipated interactions with context that can impact implementation and outcomes.

Objective: This article uses the example of the " $5 \mathrm{As}$ Team" randomized control trial to explore implementation strategies to promote knowledge transfer, capacity building, and practice integration, and their interaction within the context of an interdisciplinary primary care team.

Methods: We performed a qualitative evaluation of the implementation process of the 5As Team intervention study, a randomized control trial of a complex intervention in primary care. We conducted thematic analysis of field notes of intervention sessions, $\log$ books of the practice facilitation team members, and semistructured interviews with 29 interdisciplinary clinician participants. We used and further developed the Interactive Systems Framework for dissemination and implementation to interpret and structure findings.

Results: Three themes emerged that illuminate interactions between implementation processes, context, and outcomes: (1) facilitating team communication supported collective and individual sense-making and adoption of the innovation, (2) iterative evaluation of the implementation process and real-time feedback-driven adaptions of the intervention proved crucial for sustainable, context-appropriate intervention impact, (3) stakeholder engagement led to both knowledge exchange that contributes to local problem solving and to shaping a clinical context that is supportive to practice change.

Conclusion: Our findings contribute pragmatic strategies that can help practitioners and researchers to navigate interactions between context, intervention, and implementation factors to increase implementation success. We further developed an implementation framework that includes sustained engagement with stakeholders, facilitation of team sense-making, and dynamic evaluation and intervention design as integral parts of complex intervention implementation. (J Am Board Fam Med 2018;31: 431-444.)

Trial registration: NCT01967797. 18 October 2013

Keywords: Capacity Building, Communication, Implementation Science, Interdisciplinary Studies, Primary Health Care, Problem Solving

\section{Background}

"Theory without experimentation is empty. Experimentation without theory is blind." Bhaskar, $1978^{1}$

This article was externally peer reviewed.

Submitted 5 July 2017; revised 19 September 2017; accepted 23 September 2017.

From Department of Family Medicine, University of Alberta (TL); Department of Anthropology, University of Lethbridge (JA); Department of Medicine, Division of Endocrinology, and Alberta Diabetes Institute, University of Alberta (AMS); Lifelong Learning and Physician Learning Program, Department of Family Medicine, and Alberta Diabetes Institute, University of Älberta (DLCS).
Implementation of interventions to support practice change in primary care settings is complex. Pragmatic strategies, grounded in empiric data, are

Funding: The 5AsT study is funded by Alberta InnovatesHealth Solutions, with significant in kind support from the Edmonton Southside Primary Care Network. The researchers are independent of the study funder. The funder had no access to study data, no involvement in the design or execution of the study, no involvement in analysis, and no role in the decision to publish.

Conflict of interest: T Luig and J Asselin have nothing to disclose. AM Sharma is a member of an Advisory Board with a commercial organization [Novo Nordisk: Advisory Board for anti-obesity drug]; AM Sharma was a member of the 
needed to navigate real-world challenges that can impact implementation processes and outcomes. "Complex" refers to interventions with interacting components requiring behaviors by individuals receiving or delivering the intervention, and with variable outcomes in different contexts. ${ }^{2-4}$ Examples include educational and behavioral interventions and processes of care.

Efforts to implement complex interventions interact with individual, collective, organizational, politico-economic, and societal factors that impact the degree to which practice is actually changed..$^{5-8}$ Interventions can "fail" for 3 reasons: first, the idea may not work in practice in the context in which it was being tested; second, if the process of implementation was not meeting the needs of stakeholders; and third, if there is contextual instability such as a change in a key staff member, funding, or an unforeseen variable that impacts implementation. Navigation of implementation challenges during a trial may result in new insights that mandate a shift in approach while the intervention is ongoing. Such learning processes are invaluable yet rarely described in the literature. ${ }^{4}$ There is a call to pay detailed attention to what actually happens during

Data Safety Monitoring Board for an anti-obesity trial [Takeda]. DL Campbell-Scherer has an unrestricted educational grant from a commercial organization 6/2016 (Novo Nordisk).

Corresponding author: Denise Campbell-Scherer, University of Alberta, 2-590 Edmonton Clinic Health Academy, Edmonton, AB T6G 1C9, Canada., Phone (780) 492-7454; E-mail: dlcampbe@ualberta.ca.

Availability of data and materials: Research described here has been conducted at the University of Alberta. Deidentified data on which the conclusions of this work rely are securely stored on campus of the university. De-identified and aggregated data will be available, upon request and appropriate ethics approval, through the investigators at the University of Alberta. 5As'T materials and tools are available at http://www.obesitynetwork.ca/5As_Team.

Ethics approval and consent to participate: This study was approved by the University of Alberta ethics board, Pro00036740 and registered NCT01967797. Informed consent was obtained from all participants prior to taking part in the study.

Authors' contributions: DCS and AMS conceived of the study, wrote the grant, and supervised the project. JA led the qualitative data collection of the 5AsT study, supported by DCS. All authors had full access to data and can take responsibility for data integrity and accuracy. DCS and TL led the review of frameworks for implementation and dissemination as well as the analysis of the implementation data for the present work. TL wrote the manuscript, supported by DCS. All authors reviewed the manuscript and provided comments. implementation in the real-world context in which it is unfolding. ${ }^{4,9-12}$

Theoretic guidance is important in designing and evaluating implementation of interventions to improve health care delivery. ${ }^{5-7,13-15}$ There are a number of theories and frameworks for the organization and evaluation of implementation, both in the implementation science and continuous quality improvement literature. ${ }^{5,7,8,13,15-18}$ These constructs range from broad frameworks that allow wide applicability to prescriptive and operational models. They can consist of comprehensive lists of factors or focus on select aspects of implementation. ${ }^{14,16}$ For complex intervention implementation projects, frameworks need to do 3 things: first, they need to integrate multiple stakeholders' perspectives; second, provide pragmatic guidance as to the "how" of planning implementation processes; and third, consider the interactions between aspects of implementation and context to facilitate sustainable practice integration. When selecting an implementation approach, it is important to match the scope of the intervention and question to the purpose of the construct. ${ }^{13,15}$

The aim of the 5 As Team (5AsT) randomized control trial was to change the behavior of health professionals and the organization of care to improve care for obesity in primary care. The theoretically informed intervention was cocreated with interdisciplinary front-line clinical providers. [Box 1] $5 \mathrm{AsT}$ a priori set out to detail the implementation process as it unfolded.

The interactive systems framework (ISF) (Figure 1$)^{8}$ is one fitting structure for organizing and interpreting our findings from the implementation process evaluation of the 5 AsT trial. The ISF addresses implementation in a nonlinear manner to reflect the dynamic quality of real-world implementation. Elements include knowledge synthesis and translation, innovation support through capacity building, and innovation delivery. The ISF conceptualizes interactions between general organizational and team capacity and intervention implementation.

To date, the framework has been used to plan and evaluate implementation of research-based knowledge into practice. ${ }^{19-30}$ The process elements of implementation, represented by the pathways between the framework's components (arrows), including movement of knowledge from practice into research and theory, are not well un- 
Figure 1. The Interactive systems framework for dissemination and implementation. ${ }^{8}$ Used with permission from Springer.

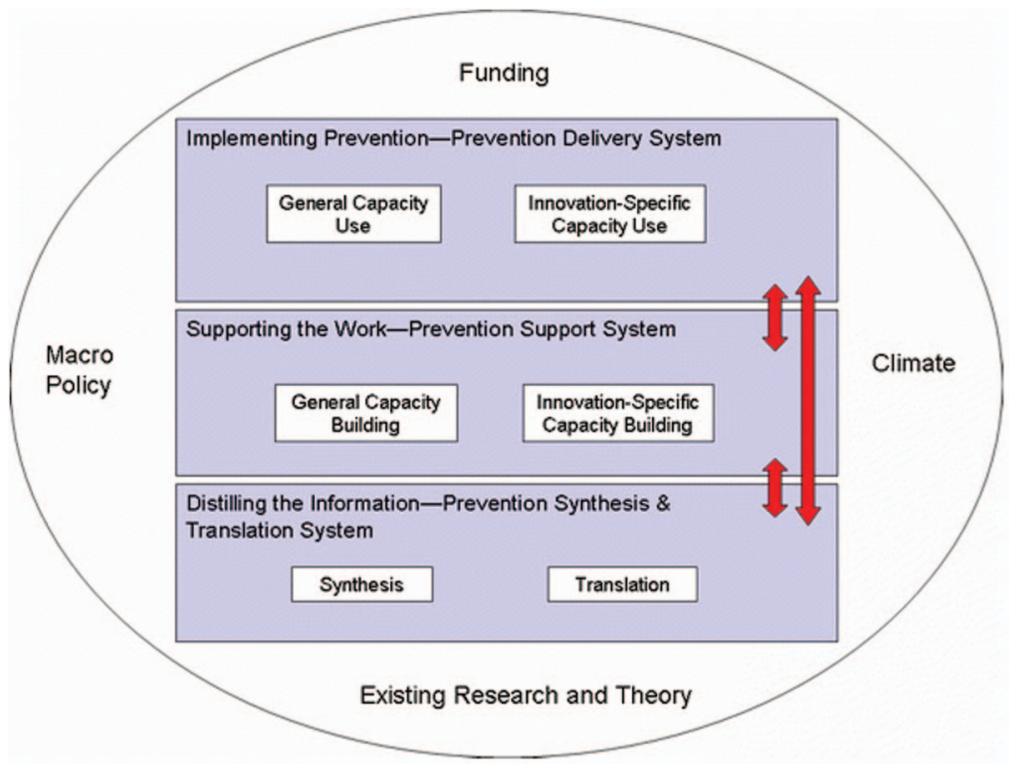

derstood. In a review of the empirical evidence for the framework, the ISF authors call for research that can help understand these pathways. ${ }^{19}$

The objective of this article is to present findings of 5 AsT that illuminate this gap in knowledge of implementation processes. Deeper understanding of the ISF and implementation processes from this empiric data provides pragmatic strategies to support sustainable primary care practice change.

\section{BOX 1: Illustrative example of a complex problem: Interdisciplinary primary care obesity management}

The "Implementation and evaluation of the 5 As of Obesity Management ${ }^{\mathrm{TM}}$ in primary care study: the 5As Team study (5AsT)" was conceived in partnership with a large, urban Primary Care Network $(\mathrm{PCN})$ as a response to the need to improve the use of evidence-informed obesity prevention and management knowledge in primary care practice. The PCN links community family practices and provides access to interdisciplinary team-based care to approximately 300,000 people in an urban centre in Canada. The study question, outcome measures, intervention design, and implementation were developed in partnership with the end users. Twenty-four clinic-based teams were randomized. Intervention team providers received a 6-month intervention cocreated with the PCN, based on their self-assessed needs. The intervention included biweekly interactive lectures on topics identified by participants, followed by facilitated learning collaborative sessions where team members shared best practices, considered logistic and clinical challenges, and created individual practice improvement goals. ${ }^{31}$ If the need for a tool arose, a graphic designer was brought in to cocreate new or adapt existing tools with participants. ${ }^{32,33}$ The study protocol, intervention design, qualitative and quantitative evaluation outcomes, created tools, and intervention materials are described elsewhere. ${ }^{31,32,34,35}$ Ethics approval was given by the University of Alberta Health Research Ethics Board-Health Panel (Pro00036740). This trial was registered via Clinical Trials. Gov (NCT01967797).

\section{Methods}

This article focuses on the findings of the thematic analysis of the qualitative data on implementation process gathered prospectively during the 5AsT trial. $^{34}$ The 5 AsT research team made an explicit effort to document the implementation process ( $\mathrm{Ta}$ ble 1) with the following goals: (1) to capture interactions with contextual factors to ensure alignment with the organization, (2) to continuously adjust implementation process to ensure it was meeting the needs of the stakeholders, (3) to use these insights to reflect on theoretical under- 
Table 1. The 5As Team (5AsT) Implementation Strategies, Methods, and Actors Structured According to the Interactive Process Framework (Figure 2)

\begin{tabular}{lll}
\hline 5AsT Strategy & Methods & Team Members and Actors \\
\hline
\end{tabular}

Flexible Intervention with Fixed Core Elements and Adaptable Periphery

Needs assessment

Expert speaker

Learning collaboratives

Co-creation of tools

Supporting learning resources

Flexible Intervention Adaptation

\section{Iterative Qualitative Evaluation}

Clinical champion and researchers

Qualitative evaluation

\section{Collective Sense-Making \\ Learning collaboratives}

Team meetings

Goal setting in learning collaboratives

\section{Engagement}

Research partnership

Practice facilitators

Clinical champion
Participants self-identified learning needs

Interdisciplinary experts addressed learning gaps

Up to date research and practice implications

Sharing of experiences, ideas, discussing needs, group activities, interactive activities

In response to identified needs search for existing tools, creation of tools, iterative with providers and graphic designers

Podcasts, tools online, and emailed one week after session

Summaries of session materials emailed after session

Change of session topics

Change of learning collaborative groups

Addition of team relationship-enhancing activities

Ongoing feedback between participants, PCN management, and research team. Clinical champion kept logbook of encounters with researchers and detailed record of all project materials and communications

Guided field notes on intervention sessions, interviews parallel to workshops [at 6 and 12 months]

Sharing of experiences, ideas, discussing needs

Group activities, interactive activities

Making explicit the implications of knowledge for practice and practicable strategies for putting them into action

PCN management as co-investigator, collaborative grant writing and intervention design, $\mathrm{PCN}$ in-kind contributions [dedicated time of clinical champion]

Clinical champion and anthropologist from the research team keep logs of their encounters and detailed record of all project materials and communications

Research team meetings, logistics, communication. Consulted on interviews, tools, problem solving, and review of codes and themes ongoing intervention, evaluation

Troubleshooting emerging barriers
Research team and clinical champion

Research team arranged expert speakers

Coordinated by clinical champion, facilitated by clinical champion, and PCN clinician trained in practice facilitation

Facilitated research team and graphic designer, and cocreated by participants

Compiled by research team, topic experts, with input from clinicians and participants

Clinical champion and research team

Clinical champion and research team

Coordinated by clinical champion, facilitated by clinical champion, and PCN clinician trained in practice facilitation

Research team, feedback from clinical champion

Learning collaborative facilitators and clinician participants

PCN administrative and senior clinical leadership

5AsT practice facilitators were the clinical champion and research team anthropologist

Clinical champion (a frontline PCN dietician) 
Table 1. Continued

\begin{tabular}{|c|c|c|}
\hline 5As'T Strategy & Methods & Team Members and Actors \\
\hline Team meetings & $\begin{array}{l}\text { Implementation evaluation update, } \\
\text { interview and analysis update, peer } \\
\text { coding, troubleshooting emerging } \\
\text { barriers, reviewing results papers } \\
\text { [dissemination] }\end{array}$ & $\begin{array}{l}\text { Research team, clinical champion, and PCN } \\
\text { administrative and senior clinical } \\
\text { leadership }\end{array}$ \\
\hline Transparency & $\begin{array}{l}\text { Open communication about } \\
\text { intervention intent, encouragement } \\
\text { of participant input }\end{array}$ & $\begin{array}{l}\text { Research team, clinical champion, and PCN } \\
\text { administrative and senior clinical } \\
\text { leadership }\end{array}$ \\
\hline \multicolumn{3}{|l|}{ Organizational Context } \\
\hline Partnership & $\begin{array}{l}\text { 5AsT as part of PCN business plan, } \\
\text { PCN in-kind contributions } \\
\text { [dedicated time of clinical champion] }\end{array}$ & $\begin{array}{l}\text { Research team and PCN administrative and } \\
\text { senior clinical management }\end{array}$ \\
\hline Clinical champion & $\begin{array}{l}\text { Navigated logistics, recruitment, } \\
\text { arranged for spaces, time, food; } \\
\text { introduced team to organizational } \\
\text { culture }\end{array}$ & $\begin{array}{l}\text { Clinical champion (a frontline PCN } \\
\text { dietician) }\end{array}$ \\
\hline \multicolumn{3}{|l|}{ Research and Theory } \\
\hline $\begin{array}{l}\text { Knowledge synthesis and } \\
\text { transformation }\end{array}$ & $\begin{array}{l}\text { Expertise on } 5 \text { As of obesity } \\
\text { management and on obesity topics, } \\
\text { snowball sampling of existing tools, } \\
\text { and cocreation and publishing of new } \\
\text { and adapted tools }\end{array}$ & $\begin{array}{l}\text { Research team, topic experts, participants, } \\
\text { graphic designer }\end{array}$ \\
\hline Implementation framework/theory & $\begin{array}{l}\text { Selection of framework for project } \\
\text { design based on focus on context, } \\
\text { after project revision of lessons } \\
\text { learned, and refinement of theoretical } \\
\text { approach }\end{array}$ & Research team \\
\hline \multicolumn{3}{|l|}{ Policy and Funding } \\
\hline PCN partnership & $\begin{array}{l}\text { Using the PCN structure and } \\
\text { autonomy to partner in research }\end{array}$ & PCN leadership \\
\hline Grant application & $\begin{array}{l}\text { Leveraging grant funding with PCN } \\
\text { in-kind contributions }\end{array}$ & $\begin{array}{l}\text { Research team and PCN administrative and } \\
\text { clinical management }\end{array}$ \\
\hline
\end{tabular}

PCN, Primary Care Network.

standings of complex interventions implementation, and (4) to allow identification of key components to implementation for consideration in other settings. Implementation strategies, methods, and actors are detailed in Table 1.

\section{Participants}

The research team included interdisciplinary researchers (family medicine, obesity experts, epidemiology, anthropology, public health), organization clinical and executive management, and a front-line dietician. The latter was a trusted staff member with special interest and experience in obesity management who took on the role of a clinical champion. The importance and efficacy of a clinical champion for facilitating implementation is well documented. ${ }^{7,31,34}$ This role includes advocating for the intervention within the organization, supporting clinicians, assisting the research team with logistics, and providing data on implementation climate during the intervention.

The 29 participants from the 12 clinics randomized to the intervention included mental health care workers $(n=7)$, registered dieticians $(n=7)$, and registered nurses or nurse practitioners $(n=15)$. One participant withdrew; their data were redacted.

\section{Data Collection and Dynamic Evaluation: Intervention Adaptation Design}

Data sources included the following: (1) semistructured interviews $(\mathrm{n}=28)$ with consenting intervention participants, (2) field notes taken during intervention sessions, (3) log book of the clinical champion, and (4) documentation of all project materials, resources, and communications. Any information relevant to the implementation process was taken note of and analyzed as data. The clinical champion was vital for on-the-spot prob- 
Figure 2. Interactive "process" framework for the implementation of complex interventions.

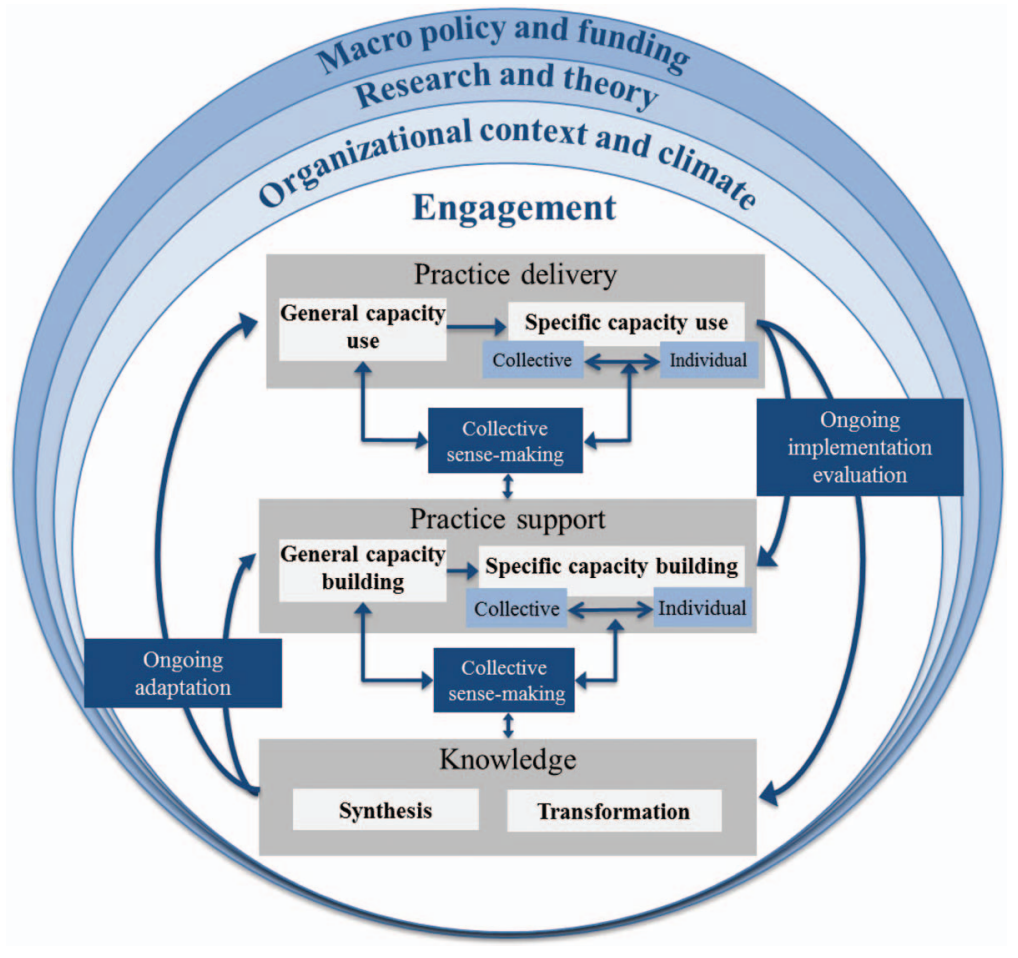

lem solving, supported the partnership, and acted as a barometer for implementation climate. Active communication between the clinical champion and the research team allowed real-time evaluation of the intervention implementation and correction of the implementation process.

\section{Analysis}

Thematic analysis was conducted using the approach described previously. ${ }^{35}$ Using NVIVO 10 software for data management, the material was inductively coded. Each code was then reviewed for recurrent patterns or subthemes, which were compared between codes to identify themes. All coding was cross-checked by research team members and a second independent $\mathrm{PhD}$ anthropologist. For the purpose of this article, codes pertaining to the pathways between the ISF components underwent a directed review for information relevant for our objective by a third $\mathrm{PhD}$ anthropologist. These include the following: (1) movement of knowledge into individual and team capacity building, (2) capacity building to practice integration, (3) interactions of implementation processes with context, and, (4) bidirectional movement between research and practice.

\section{Results}

Three novel themes emerged from the 5AsT implementation process analysis that illuminate areas of interaction between the ISF implementation processes: (1) collective sense-making, (2) dynamic evaluation and implementation process adaption, and (3) consistent engagement with stakeholders. These process elements were crucial for implementation success (Figure 2).

In addition, 5AsT implementation findings that speak to the existing components of the ISF overlap with the 5AsT main outcomes, published elsewhere. ${ }^{35,36,37}$ Most notably, we found ISF's consideration of general team capacity and its impact on an individual's capacity building extremely important. ${ }^{36,37}$

Our results illuminate the pathways between knowledge transformation, practice support, and practice delivery (Figure 2). They exemplify pragmatic strategies for achieving sustainable practice change. Because of the dynamic design of the implementation process, it is essential for this section to include both a description of the implementation strategies and findings of the 5AsT trial implementation process evaluation. Supporting data are presented in Table 2. 
Table 2. Supporting Data on 5As Team Implementation Process from Participant Interviews and Field Notes

Finding $\quad$ Representative Quotes, Field Notes, and Examples

Knowledge (synthesis and transformation)

Practice support (team and individual capacity building)
Practice delivery

\section{Collective sense-making}

A2: I really liked it. It was really just kind of asking us what we want to learn and what we find we can use to help patients so it's really, I like that it's focused on us and what we want to learn.

A11: I like that you guys ask us what our needs are and, and, and that kind of helps bring in what, what's relevant to us

C6: I was feeling positive about my knowledge and my beliefs in it but I wasn't very good at sharing them to other people so there's been a little bit more of that since I've done it, I can talk more comfortably and not be so afraid to kind of challenge some of the physician's statements and opinions so that's been helpful to feel a little bit more, more assertive I guess in that and have something to back it up with so.

A3: I was really excited. I'm going, actually the first morning back I went around to all the doctors and gave them a copy of each of the, the tear offs saying you know this is, you know this is finally actually on one piece of paper, the approach we've been using with weight.

A14: I will see someone and then or $X$ will see somebody, our dietician and say you know what, you need to go see $X, \ldots$, you know you're not ready to deal with any of these, we have to deal with this first and so I think we've really been more conscious and doing that more even since we were all involved with this research so and we work together, you know . . . will meet with some patients together and come from two perspectives and then say you know what, I think you need to see $X$.

Field notes from learning collaboratives:

- Laughter and joking were not uncommon and they increased as the sessions went on. This is evidence of a friendly atmosphere.

- Likewise discussion around tools, particularly the physical activity guidelines tool, which was critiqued quite a bit, is evidence of an open and sharing atmosphere.

B4: Fust collaborating at the end, having an open discussion, getting perspectives from different health care professionals is always good too and like even for today, we identified gaps in terms of the classes that we were offering for nutrition so it brought to light something like change right that can happen so it's good. I've, I've really enjoyed it.

A11: It's really good. One thing that I have addressed is that in the waiting room we don't have any bariatric chairs, which can be a little bit uncomfortable so I have ordered those through the PCN for the clinic and for my office as well.

B2: Yeah, well the one clinic where the scale was in the front entrance, I moved it to the back room into the clinic or in the office where I was and it was fine so.

Interactional findings:

B2: Yeab I really like that. I like doing that because then you can learn something, then you talk with everybody about certain things and then you could try it in their clinic if you can so.

B6: I like the breakout sessions so we get a chance to talk about and how it applies to our settings and to patients, I like that part of it.

A5: I thought it was very good. I especially enjoyed today. I think it gives us new ways to look at things and I think we need each other's ideas because lots of times there's just one little thing that somebody else does that you never thought of and if we, if we work in isolation, you know if we never bave meetings then and we always do the same thing with patients, we don't get any new ideas and I think that's important in learning, you know trying different things. Maybe it won't work but at least you've tried or, or it gives you another idea.

Field notes from learning collaboratives:

- There are many examples of provider troubleshooting what they are learning with the realities of its application in clinics. Example: how to ask with very sensitive patients, or how to deal with weight bias when the doctor is the problem?

- There are examples of providers sharing ideas, little tricks, and often, specific wording of issues or questions that work well for them with patients. 


\begin{tabular}{|c|c|}
\hline Finding & Representative Quotes, Field Notes, and Examples \\
\hline & $\begin{array}{l}\text { There was often rich discussion around topics wherein providers } \\
\text { clarified any misunderstandings and found a common understanding of } \\
\text { topics/facts/ideas that were brought up during the talk. }\end{array}$ \\
\hline \multirow[t]{7}{*}{ Dynamic intervention and evaluation design } & Example of feedback that led to project adjustment \\
\hline & $\begin{array}{l}\text { A10: I think the facilitator should rotate or I don't think you're going, I think } \\
\text { the group altogether is too big so I think they should try to rematch the } \\
\text { groups a bit because there's certain, like the group I'm in is a very quiet } \\
\text { group }\end{array}$ \\
\hline & Field notes \\
\hline & $\begin{array}{l}\text { Deliberate introductions between participants are necessary and should } \\
\text { be planned. }\end{array}$ \\
\hline & $\begin{array}{l}\text { Deliberate planning and strong facilitation of learning collaboratives: } \\
\text { using quiet time before goal setting, trying different approach to } \\
\text { encourage responses. }\end{array}$ \\
\hline & Print-outs of materials and providing binders work well. \\
\hline & $\begin{array}{l}\text { Group activities and interactive methods (writing on charts, using sticky } \\
\text { dots) were well received and could be used more often. }\end{array}$ \\
\hline \multirow[t]{2}{*}{ Engagement } & Examples \\
\hline & $\begin{array}{l}\text { Intervention focus and design was reached through collaboration with } \\
\text { the organization. Open communication was maintained by all } \\
\text { involved. Study length, focus, and intensity were agreed upon through } \\
\text { detailed discussion with the organization management and staff. }\end{array}$ \\
\hline
\end{tabular}

$\mathrm{A}=$ Nurse

$\mathrm{B}=$ Dietician

$\mathrm{C}=$ Mental Health Consultant.

\section{Collective Sense-Making}

A key factor for implementation that drove success was a strategy to promote space and time for team relationships and communication. This was crucial to foster collective sense-making of new knowledge for application in the specific practice contexts. Sense-making happened at the individual and collective level and integrated the information with previous experience, clinic context, and existing practice approach. This integration occurred in formal and informal communicative spaces, including emails, notes, and hallway chats. Learning collaboratives, a part of the 5AsT implementation strategy, were successful in deliberatively creating a positive space for interdisciplinary team members to share experiences and negotiate a collective approach to weight management. These were facilitated by PCN staff to increase a sense of ownership in the participants in the process.

Participants reported that they appreciated the team-based discussions, which facilitated sharing experiences, troubleshooting challenges, and developing mutual understanding of the new approach. As a result, participants reported improved confidence for interdisciplinary collaborations, improved team relationships, and individual and col- lective self-efficacy. Team communication was a clear variable that affected practice change. A key learning for the organization moving forward was the need to foster effective team development.

\section{Dynamic Evaluation and Implementation Process Evaluation}

Our data support the ISF in suggesting that knowledge transformation, capacity building, and delivering practice change do not unfold in a linear fashion. During the 5 AsT implementation, the core messages of the intervention remained central and stable. The intervention process was dynamic. The team collaboratively sought solutions, adapted the intervention process in response to participant concerns, and negotiated the "how" of applying the new knowledge in individual practices.

After each intervention session, the research team discussed feedback from field notes, provider interviews, observations, and session summaries. If a need to change or add material was identified, the team adapted accordingly. Although the key content messages of the intervention were kept consistent, specific topics responded to provider needs in their particular context. Some challenges, such as repetition between speakers and 
topics that could not be covered or were oversimplified, arose and were mitigated.

The dynamic design and iterative evaluation of the implementation process allowed the research team to respond to emerging barriers and continuously ensure intervention appropriateness for participants. For example, during one intervention session, providers expressed their interest in learning about weight gain prevention. When a speaker cancelled a subsequent session, the team was able to arrange a new session on prevention to take its place. The team collaboratively identified and created new tools and resources when requested by participants. The mode of delivery was modified to include role-playing when participants expressed the need to do so. In another example, by chance at the outset of the intervention, the learning collaborative groups, which had 6 clinic teams each, were found to have more extroverted participants in one group. Participants identified this as a problem and opted as a group to rebalance the learning collaboratives to better facilitate lively discussions. As a result, we observed increased collegiality, sharing, and comfort between participants. Permitting such flexible implementation, while keeping the core principles consistent, allowed the intervention to be meaningful and applicable to the providers.

\section{Consistent Engagement with Stakebolders}

Transparent communication and partnership between the organization management, researchers, and the clinical champion supported all stages of formulation of the research question, intervention design, grant writing, implementation, and evaluation. 5AsT responded to the desire of a primary care organization to improve practice. This collaboration, grounded in both research and practice, was integral to the 5AsT knowledge synthesis and transformation activities.

Once funding was secured, the team designed the intervention to allow flexibility around the specific learning content and methods, with the intention to engage participants in adapting the intervention to meet their needs. ${ }^{31}$ The research funding supported the intervention creation and evaluation, while existing clinical funding supported the intervention delivery, learning collaborative facilitation, and all clinical operations. The PCN management specified processes for working with the participants. The participants determined the content of the intervention, and the research team facilitated the logistics of the creation and delivery of the program. With the help of the clinical champion, speakers were briefed about the organizational environment, so they could adjust their presentations and discuss relevant practice implications. As a result, the project was perceived as appropriately addressing organizational needs, as useful for providers' daily practice, and as resulting in practical changes that were sustainable once research funding ceased.

As a challenge, providers noted the difficulty to make time to participate. Building capacity and changing practice required work and commitment from individuals and teams. However, management and participants emphasized that they perceived the intervention as providing a solution for their own practice and, therefore, considered the time commitment worthwhile.

\section{Discussion: Understanding the In-Between: The Interactive Process Framework for the Implementation of Complex Interventions}

The implementation of interventions to support practice change in primary care settings is key for continuous improvement. Empiric, prospective data from the 5AsT randomized control trial provide useful insights into pragmatic strategies to navigate real-world challenges that can impact implementation processes and outcomes. These strategies include collective sense-making achieved through creating opportunities to foster team communication and relationships, active monitoring of implementation processes to identify challenges, and creation of a shared vision through stakeholder engagement throughout the project. Key findings also emerged from exploring interactions of context with implementation activities, such as knowledge exchange, capacity building, and practice integration.

The ISF was further developed with our main findings, which illuminate the 3 areas of interaction between the ISF components. As a result, we propose the Interactive Process Framework for the implementation of complex interventions (Figure 2). This enhanced framework has the potential to be applied beyond its original focus on prevention projects and to inform the collaborative design and evaluation of a variety of complex interventions.

The original ISF speaks of "knowledge translation," a term that, while defined differently in different contexts, prioritizes scientific research find- 
ings as knowledge. ${ }^{38,39}$ Our findings support the notion that there is a complex social process of negotiating knowledge-in-context-in-practice by individuals and collectives that goes beyond collaborative knowledge exchange and mutual learning; thus, we follow Gabbay and Le May ${ }^{40}$ and use the term "knowledge transformation." Knowledge transformation includes the integration, adaptation, and negotiation of research knowledge to best address the challenges of practice settings, as well as tacit knowledge from lived experience of practice to further develop research and theory. To avoid a static notion for the ISF components, stemming from the term "systems" (see Figure 1), we will use the following terms: (1) knowledge transformation, (2) practice support, and (3) practice delivery processes (see Figure 2).

\section{Moving between Knowledge, Support, and Delivery Processes: Collective Sense-Making}

The importance of individual and collective sensemaking to integrate new knowledge into practice is supported by the literature. Processes of shaping and changing individual and team practice have been examined ethnographically in primary care settings by Gabbay and Le May ${ }^{40}$, who found that once new information is available to clinicians, "it is collective, social processes that are instrumental in processing and combining it into internalized knowledge-in-practice-in-context." Their research suggests that clinicians synthesize knowledge not only from research evidence or new guidelines but also from colleagues, opinion leaders, previous training, experiences with patients, and other tacit knowledge. What is negotiated in such collective and iterative processes are "collectively reinforced, internalized tacit guidelines" or, as coined by Gabbay and Le May ${ }^{40,41}$, "mindlines." Individual and collective mindlines mutually shape each other as team members share stories, debate challenges, or question new or existing guidelines. They develop communities of practice in which knowledge is nurtured, negotiated, and used as corrective against which individuals check and revisit their own mindlines. ${ }^{42}$ It follows that the facilitation of team relationships and communication should constitute an important aspect of implementation efforts and a vital part of the intervention itself, especially where multiple clinic sites and interdisciplinary teams complicate the development of communities of practice.

Another crucial aspect of collective sense-making is the associated redefinition of professional identities. ${ }^{40}$ During the 5 As T project, this was evident, as different health professionals became aware of the role they and their disciplinary perspective can play in weight management. This was also evident when team members initiated change in their clinic environment and weight management approach to be more inclusive and respectful of people with larger bodies.

The Normalization Process Theory (NPT) supports the relevance of our findings for sustained practice change. NPT is a midrange theory to explain and evaluate how complex interventions become routinized in their organizational context. According to NPT, 4 mechanisms are involved when individuals and teams work together to embed a new practice: coherence (or sense-making), cognitive participation (or commitment and relational work), collective action, and reflexive monitoring (or appraisal). ${ }^{2,43,44}$ The 5AsT intervention implementation strategies, such as cocreation of the intervention, collective sense-making, developing communities of practice, and redefining professional identities in light of new knowledge, can be understood as examples of NPT mechanisms. Coherence, for example, involves recognizing the innovation as different from established practices and as having the potential to solve perceived challenges. The 5AsT project achieved such differentiation by designing the intervention based on needs that were identified by management and clinicians of the organization. Coherence also implies communal sense-making and internalization, which is evident in the 5 AsT findings.

\section{Moving along the Circle: Dynamic Evaluation and Intervention Implementation Adaptation}

Continuous evaluation from multiple data sources (Table 1) and space for flexible adaptation of the intervention allow for appropriate adjustments when barriers or contextual changes emerge. ${ }^{34}$ Greenhalgh and colleagues ${ }^{5,45}$ refer to this as "fuzzy boundaries" of an intervention that can be adapted to contextual needs, as opposed to the vital elements that are maintained as the "hard core" of the intervention. The authors underscore this need for flexibility and argue that the intervention has a greater chance of adoption if practitioners can 
adapt, refine, or modify the innovation according to their particular needs and circumstances. ${ }^{5}$ Despite the challenges that a flexible approach poses for a trial protocol, ${ }^{2,4}$ we found that the impact of the intervention depends vitally on this dynamic design. Iterative evaluation in conjunction with an adaptable intervention provides pathways for evidence-based and practice knowledge to move between the intervention's activities, clinical practice, organizational context, and researchers. As Gabbay and Le May ${ }^{40}$ argue, in the process of constructing individual and collective mindlines, clinicians continuously refine their approach based on challenging experiences, unexpected events, new information, or organizational changes. This collective evaluation links tacit knowledge and clinical experience with ongoing knowledge transformation activities and capacity building in a dynamic, cyclic process.

Given the interactive quality of how clinicians individually and collectively make sense of new knowledge and transform it into knowledge-inpractice-in-context, we argue that a flexible intervention and implementation design with consistent core features is vital for the embedding of new knowledge in practice. The adaptiveness and responsiveness of an innovation to the individuals' and teams' social processes of sense-making become vital attributes of the intervention. ${ }^{5,40,45}$

\section{Connective Tissue: Continuous Engagement and Co-constructing Context}

Engagement throughout all stages of the 5AsT project served as connective tissue without which the pathways for moving knowledge, feedback, and contextual expertise would not have been effective. The inclusion of practitioners and management in the research team set the stage for an ongoing partnership. The clinical champion was vital in facilitating engagement with individuals and the team throughout the project. ${ }^{5,7}$ Such a partnership approach addresses the issue of power relations that can impact providers' autonomy, agency, and sense-making with regards to new knowledge or a new practice. ${ }^{46-48}$

The 5 As $\mathrm{T}$ findings confirm that a collaborative assessment of capacity needs, both with the organization's management and staff, is crucial in selecting and preparing research knowledge for use in the clinical context. The knowledge synthesis and transformation that result from such collaboration contribute to an intervention that makes sense to practitioners and is compatible with their clinical reality. $5,40,43,45$

Engagement and the dynamic intervention design were decisive in co-constructing a clinical environment that supported the intervention and practice change toward improved interdisciplinary weight management. We argue with Gabbay and Le May ${ }^{40}$ that context cannot be considered separate from actors and actions because actors (providers, management, research team, funders, and policy makers) interact to construct clinical reality. As illustrated in the adapted Interactive Process Framework (Figure 2), engagement allows constructive cross-fertilization between implementation project and contextual elements (organizational context, research and theory, and policy and funding). From this perspective, this present work is situated at the intersection of implementation processes and research and theory. Our findings contribute to the refinement of theoretic approaches to designing and evaluating intervention implementation and offer practical strategies to support sustainable and context-appropriate implementation of complex interventions.

\section{Strengths and Limitations}

The strength of our argument lies in its empiric foundation and detailed documentation of the implementation process of a complex intervention in a real world practice setting. Furthermore, the proposed framework offers 3 pragmatic strategies that researchers and practitioners can use to facilitate implementation success. Although a limitation of our study is that the qualitative approach does not allow for generalization, these strategies are well supported by theoretic literature and may be adaptive to different contexts and wider application.

\section{Conclusion}

Understanding the processes of implementation and uptake of complex interventions is crucial for explaining how evidence-based research knowledge and contextual, experiential knowledge of clinicians work together to improve health care. When lessons learned from such processes are used to inform theoretic approaches, we can be better prepared to plan, design, and evaluate the implementation of complex interventions. We have used our findings to propose the Interactive Process Frame- 
work, which provides pragmatic strategies for sustainable implementation of complex interventions in a variety of contexts.

Our empiric data and theory-based concepts link implementation processes, context, and outcomes. We found that adaptiveness and responsiveness of the innovation to the individuals' and teams' social process of sense-making become vital attributes of the intervention and key to achieving effective implementation and change. This is supported by creating space and time for fostering team relationships and communication to support shared sensemaking. Dynamic evaluation and implementation process adaption are foundational to navigating real-world challenges. Consistent engagement with stakeholders is key to ensure context appropriateness, alignment of priorities, and integration of research and tacit knowledge in practice.

The authors thank the 5As research team (R. Anderson, S. Fielding, AM Osunlana, AA. Ogunleye, JA Johnson, A. Cave, D. Manca, C. Rueda-Clausen, and M. Heatherington) and the Edmonton Southside Clinical Network for their support on the overall 5AsT Program on which this work is based. We would also like to thank G. Noel and J. Frascara for their design feedback of the framework graphic and Dr Milton Eder for his thoughtful feedback.

To see this article online, please go to: http://jabfm.org/content/ 31/3/431.full.

\section{References}

1. Bhasker R. A realist theory of science. 2nd ed. Harvester/Humanities: Sussex and New Jersey; 1978.

2. May CR, Johnson M, Finch T. Implementation, context and complexity. Implement Sci 2016;11: $1-12$.

3. Petticrew M. When are complex interventions "complex"? When are simple interventions "simple"? Eur J Public Health 2011;21:397-8.

4. Campbell-Scherer D, Saitz R. Improving reporting and utility of evaluations of complex interventions. Evid Based Med 2015, Nov 25; ebmed-2015-110342.

5. Greenhalgh T, Robert G, Macfarlane F, Bate P, Kyriakidou O. Diffusion of innovations in service organizations: Systematic review and recommendations. Milbank Q 2004;82:581-629.

6. Murray E, Treweek S, Pope, et al. Normalisation process theory: A framework for developing, evaluating and implementing complex interventions. BMC Med. 2010;8:63-73.

7. Helfrich C, Weiner B, McKinney M, Minasian L. Determinants of implementation effectiveness: Adapting a framework for complex innovations. Med Care Res Rev 2007;64:279-303.
8. Wandersman A, Duffy J, Flaspohler P, et al. Bridging the gap between prevention research and practice: The interactive systems framework for dissemination and implementation. Am J Community Psychol. 2008;41(3-4):171-81.

9. Glasziou P, Meats E, Heneghan C, Shepperd S. What is missing from descriptions of treatment in trials and reviews? BMJ. 2008;336:1472.

10. Abell B, Glasziou P, Hoffmann T. Reporting and replicating trials of exercise-based cardiac rehabilitation: do we know what the researchers actually did? Circ Cardiovasc Qual Outcomes 2015;8:18794.

11. Dal-Ré R, Bracken MB, Ioannidis JPA. Call to improve transparency of trials of non-regulated interventions. BMJ 2015;350:h1323.

12. Pawson R, Greenhalgh T, Harvey G, Walshe K. Realist review-a new method of systematic review designed for complex policy interventions. J Health Serv Res Policy 2005:10(Suppl 1):21-34.

13. Nilsen P. Making sense of implementation theories, models and frameworks. Implement Sci 2015;10:53.

14. Harvey G, Fitzgerald L, Fielden S, et al. The NIHR collaboration for leadership in applied health research and care (CLAHRC) for greater manchester: combining empirical, theoretical and experiential evidence to design and evaluate a large-scale implementation strategy. Implement Sci 2011;6:96.

15. Tabak RG, Khoong EC, Chambers DA, Brownson RC. Bridging research and practice. Am J Prev Med 2012;43:337-50.

16. Meyers DC, Durlak JA, Wandersman A. The quality implementation framework: A synthesis of critical steps in the implementation process. Am J Community Psychol. 2012;50(3-4):462-80.

17. Kaplan HC, Brady PW, Dritz MC, et al. The influence of context on quality improvement success in health care: A systematic review of the literature. Milbank Q 2010;88:500-59.

18. Ferlie EB, Shortell SM. Improving the quality of health care in the United Kingdom and the United States: A framework for change. Milbank Q 2001;79: 281-315.

19. Flaspohler P, Lesesne CA, Puddy RW, Smith E, Wandersman A. Advances in bridging research and practice: Introduction to the second special issue on the interactive system framework for dissemination and implementation. Am J Community Psychol. 2012;50(3-4):271-81.

20. Brodowski Ml, Counts JM, Gillam RJ, et al. Translating evidence-based policy to practice: A multilevel partnership using the interactive systems framework. Fam Soc J Contemp Soc Serv 2013;94:141-9.

21. Chambers D. The interactive systems framework for dissemination and implementation: Enhancing the opportunity for implementation science. Am J Community Psychol 2012;50(3-4):282-4. 
22. Collins C, Edwards A, Jones P, Kay L, Cox P, Puddy R. A comparison of the interactive systems framework (ISF) for dissemination and implementation and the CDC division of HIV/AIDS prevention's research-to-practice model for behavioral interventions. Am J Community Psychol. 2012;50(3-4):518-29.

23. Florin P, Friend K, Buka S, Egan C, Barovier L, Amodei B. The interactive systems framework applied to the strategic prevention framework: The Rhode Island experience. Am J Community Psychol. 2012;50(3-4):402-14.

24. Gregory H, Van Orden O, Jordan L, et al. New directions in capacity building: Incorporating cultural competence into the interactive systems framework. Am J Community Psychol. 2012;50(34):321-33.

25. Halgunseth L, Carmack C, Childs S, Caldwell L, Craig A, Smith E. Using the interactive systems framework in understanding the relation between general program capacity and implementation in afterschool settings. Am J Community Psychol. 2012; 50(3-4):311-20.

26. Lane R, Berkowitz J, Sullivan S, et al. Applying the interactive systems framework to the dissemination and adoption of national and state recommendations for hypertension. Am J Community Psychol. 2012; 50(3-4):541-52.

27. Noonan R, Wilson K, Mercer S. Navigating the road ahead: Public health challenges and the interactive systems framework for dissemination and implementation. Am J Community Psychol. 2012; 50(3-4):572-80.

28. Rapkin B, Weiss E, Lounsbury D, et al. Using the interactive systems framework to support a quality improvement approach to dissemination of evidence-based strategies to promote early detection of breast cancer: Planning a comprehensive dynamic trial. Am J Community Psychol. 2012;50(3-4):497517.

29. Ray M, Wilson M, Wandersman A, Meyers D, Katz J. Using a training-of-trainers approach and proactive technical assistance to bring evidence based programs to scale: An operationalization of the interactive systems framework's support system. Am J Community Psychol. 2012;50(3-4):415-27.

30. Smythe-Leistico K, Young C, Mulvey L, et al. Blending theory with practice: Implementing kindergarten transition using the interactive systems framework. Am J Community Psychol. 2012;50(34):357-69.

31. Ogunleye A, Osunlana A, Asselin J, Cave A, Sharma AM, Campbell-Scherer DL. The 5As team intervention: bridging the knowledge gap in obesity management among primary care practitioners. BMC Res Notes [Internet]. 2015 Dec [cited 2016 Jan 21];8(1). Available from: http:// www.biomedcentral.com/1756-0500/8/810.
32. Osunlana AM, Asselin J, Anderson R, et al. 5As Team obesity intervention in primary care: development and evaluation of shared decision-making weight management tools. Clin Obes. 2015;(4): 219.

33. The 5As Team Project [Internet]. [cited 2016 Apr 2]. Available from: http://www.obesitynetwork.ca/5As_ Team.

34. Campbell-Scherer DL, Asselin J, Osunlana AM, et al. Implementation and evaluation of the 5As framework of obesity management in primary care: design of the $5 \mathrm{As}$ Team (5AsT) randomized control trial. Implement Sci. 2014;9:78.

35. Asselin J, Osunlana AM, Ogunleye AA, Sharma AM, Campbell-Scherer D. Missing an opportunity: the embedded nature of weight management in primary care. Clin Obes. 2015 Aug 25;5:325-32.

36. Asselin J, Osunlana A, Ogunleye A, Sharma A, Campbell-Scherer D. Challenges in interdisciplinary weight management in primary care: lessons learned from the 5 As Team study. Clin Obes. 2016;6:124-32.

37. Asselin J, Salami E, Osunlana AM, et al. Impact of the 5 As Team study on clinical practice in primary care obesity management: a qualitative study. CMAJ Open. 2017 Apr 26;5(2):E322-9.

38. Graham ID, Logan J, Harrison MB, et al. Lost in knowledge translation: Time for a map? J Contin Educ Health Prof 2006;26:13-24.

39. Brauer P, Connor Gorber S, Shaw E, et al. Recommendations for prevention of weight gain and use of behavioural and pharmacologic interventions to manage overweight and obesity in adults in primary care. CMAJ 2015;187:184-95.

40. Gabbay J, Le May A. Practice-based evidence for healthcare: Clinical mindlines. Abingdon, Oxon, UK: Routledge, 2011.

41. Wieringa S, Greenhalgh T. 10 years of mindlines: A systematic review and commentary. Implement Sci 2015;10:45.

42. Wenger E. Communities of practice: Learning, meaning, and identity. Cambridge, UK: Cambridge University Press; 1998.

43. May C, Finch T. Implementing, embedding, and integrating practices: An outline of normalization process theory. Sociology 2009;43:535-54.

44. Lloyd A, Joseph-Williams N, Edwards A, Rix A, Elwyn G. Patchy "coherence": Using normalization process theory to evaluate a multi-faceted shared decision making implementation program (MAGIC). Implement Sci $2013 ; 8: 102$.

45. Denis J-L, Hébert Y, Langley A, Lozeau D, Trottier L-H. Explaining diffusion patterns for complex 
health care innovations. Health Care Manage Rev. 2002;27:60-73.

46. Minkler M, Wallerstein N. Community-based participatory research for health: From process to outcomes. San Francisco, CA: John Wiley \& Sons; 2011.758 p.
47. Hall BL. From margins to center? The development and purpose of participatory research. Am Sociol 1992;23:15-28.

48. Cornwall A, Jewkes R. What is participatory research? Soc Sci Med 1995;41:1667-76. 